\title{
Education and poverty trap: Evidence from mountian ar- eas in Sichuan province
}

\author{
Liang Yue*
}

Nanjing Foreign Language School, Nanjing, China

\author{
Keywords \\ Education \\ Parental beliefs \\ Poverty trap \\ Developing area \\ Received: 12 January 2020 \\ Accepted: 18 March 2020 \\ Published: 29 September 2020
}

\begin{abstract}
This study sketches a portrait of education investment for villagers in Daliang Mountain in Sichuan province with a detailed survey for parents. Those families have below-average income and receive government support on the 9 -year compulsory education. The survey data shows that parents with a higher expectation of return on education are more likely to spend more time with their children on homework and tutoring, but monetary expenditure on education is insignificant. Also, children whose parents expect a higher return on education are less likely to drop out of school. Both the direct costs (e.g., tuition) and indirect costs (forgone income because of schooling) do not significantly impact education investment. In terms of time preferences, more patient parents desire a higher level of education for their children. In summary, with government funding, the financial concern is not the major constraint for education investment for most families, but parents' attitudes and beliefs play a more important role. Based on the findings, useful suggestions for parents, government and policy makers have been made.
\end{abstract}

(C) 2020 The Author(s). Published by TAF Publishing

\section{INTRODUCTION}

Despite the Chinese government's effort to reduce educational cost for households, we still observe high dropout rates among poor students, especially in rural area. Since tuition fees were exempt for the nine-year compulsory education, direct educational cost (including tuition fees, textbook fees) cannot be the binding constraint for education for most households. In this paper, we aim to examine other factors that lead to the underinvestment in education by surveying households in mountain areas in Sichuan province.

We first present a theoretical framework, which follows Becker (2009) and views education as an investment which involves current cost and future returns. Under this framework, we can disentangle the reasons for underinvestment in education into three dimensions: perception of benefits, perception of costs and time preferences. Intuitively, if we see education as an investment in human capital, the benefits of education can be reflected by wage differences. Hall and Jones (1999) calculated from international data that on average the returns on education are around $13.4 \%$ per year for first four years of schooling, 10.1\% per year for the next four years. Bhuller, Mogstad, and Salvanes (2017) estimated an $11 \%$ rate of return on education for Norwegian population. More broadly, Ng and Feldman (2009) finds that education is positively correlated with core task performance, creativity and citizenship behaviors, and negatively related to on-the-job substance use and absenteeism. Despite the positive impact of education on human capital, Webber (2014) points out that the return to education varies greatly by institutional quality, discipline and individual characteristics. Also, people have dispersed beliefs in returns on education. Arellano (2017) shows that beliefs, aspirations and values in relation to education shapes parental ways of involvement among Chilean urban lowermiddle-class parents. Therefore, parents's beliefs in return on education play an important role in educational investment: those who believe that education will yield higher

\footnotetext{
* corresponding author: Liang Yue

†email: yueliang20030224@163.com
} 
wage in the future will invest more heavily on their children's education. The cost of education includes both direct costs, such as tuition fees, and indirect costs, such as the forgone earnings if their children work instead of going to school. Since acquisition of education is a significant investment, poverty can constitute an impediment to acquiring education and widespread government support to education help reduce cost of education. Zhang (2014) records that the cost of higher education is beyond low- and middle- income families' affordability. Deininger (2003) finds that Uganda's program of "Universal Primary Education" which dispensed with fees for primary enrollment was associated with a dramatic increase in primary school attendance. Orazem and King (2007) analyzes the effect of different government policies (subsidies of schooling costs, vouchers and unconditional income transfers) on levels of schooling. Although the government support and free basic education in poor areas greatly reduces the direct cost of education, the indirect costs can still be the liquidity constraint for educational attainment for those poor households. Voiculescu (2009) provides a model of applying opportuinity cost concept on investments in human educational capital and documents that the share of opportunity cost is around $60 \%$ of the total costs of education. Moreover, as an investment activitiy, the cost incurs in the current period whereas the benefits come in the future. Therefore, parents' time preferences also play an important role in determining their children's years of schooling. Those who are more patient place higher weight on future benefits and those who are more impatient cares more about the current costs. Eckel, Johnson, and Montmarquette (2013) finds that patience and risk preferences are key to understanding the determinants of educational investment for low-income individuals in a lab experiment. Patient participants were more likely to save for a family member's education. Therefore, it's reasonable to assume that more patient parents tend to invest more on their childrens' education.

To test the predictions above, we conducted a survey in Daliang Mountain in Sichuan province, China. The income level in that area is below average and $39 \%$ of households in that area had at least one child who dropped out from school. We established a long-term relationship with local primary schools there by voluntary teaching and managed to suvey parents of children from those schools. The survey questions covered parents' beliefs about the return on education, their beliefs about indirect cost of education, and standard measures of time preferences, which allows us to direct test the predictions of the theoretical framework. Despite the limited sample size, we managed to sketch the overall picture of parents' beliefs about benefits and costs of education. We also tried to link those parents' beliefs with household characteristics and real educational outcomes for their children. The main outcome variable that we are interested in are measures of investment in education, including dropout rates, educational expenditure, and time spent with children on their education.

Consistent with the theoretical model, we find children whose parents have higher expectation of return on education are less likely to droup out from school, and their parents are also more likely to spend more time with them on tutoring and homework. However, parents' perception of costs of education does not have significant impact on education investment (measured by dropout rates, monetary and time investment). This could partly be explained by the government's policy that aims at reducing the burden of basic education in poor rural area. Furthermore, consistent with the prediction on time preferences by the model, we observe positive correlation between parents' patience level and children's education.

The paper is organized as follows. Section I reviews the literature on education, especially in developing area. Section II discusses our Research Methodology, including the description of sampling of the survey and research hypotheses. Section III presents the theoretical framework and its predictions. Section IV discusses the empirical results from the survey. And finally, we conclude and discuss potential future research in Section $V$.

\section{LITERATURE REVIEW}

\section{Education and Human Capital, Theory}

Smith (1776) described human capital in the following way: "the improved dexterity of a workman may be considered in the same light as a machine or instrument of trade which facilitates and abridges labor, and which, though it costs a certain expense, repays the expense with a profit." Early works sucha s Shultz (1953), Mincer (1962) also discussed the economic value of education. Altonji (1993) used a model to explore the effects of ability, preferences for schooling, ex post payoffs to college on the probability of college outcomes and ex ante return to starting college. Heckman, Humphries, and Veramendi (2018) estimated the return to education using a dynamic model of educational choice that accounts for heterogeneity in cognitive and noncognitive skills and the Becker (2009) established one of the most influential framework in analyzing education as an investment in human capital. Human capital is defined as individual's productive skills, talents and knowledge. Education and training raise the productivity of workers by imparting 
useful knowledge and skills. In Becker (2009), education is viewed as an investment where agents maximize the discounted benefit minus costs of education.

The assumpotions involved are that agents are well informed and have rational expectations about the return on education. Specifically, returns on human capital investment are generally inferred from differences in wages among people with different levels of education. Hall and Jones (1999) calculated from international data that on average the returns on education are around $13.4 \%$ per year for first four years of schooling (grades 1-4), 10.1\% per year for the next four years (grades 5-8) and 6.8\% per year for each year beyond eight years. Bhuller et al. (2017) used Norweigian population panel data and estimated an internal rate of education of around $11 \%$. However, there exists no clear evidence whether people have the correct beliefs about the return on education. We contribute to this literature by directly eliciting parents' expetations about return on education and examine whether those expectations have an impact on education decisions for their children.

\section{Education and Human Capital, Empirical}

There exists plenty of evidence showing the effect of education on children's earnings and future development. Chetty, Friedman, and Rockoff (2014) shows that education quality, even as early as kindergarten, has large impact on kid's lives. They use the Tenesse STAR experiment which randomized students into different classrooms in Kindergarten and find that better classrooms had large impacts on college attendance, earnings etc. Chetty et al. (2014) use the "value-added" approach to analyze the effect of teachers. They found that high quality elementary teachers generate large long-term gains for students, including higher college attendance ratesa and larger earnings. Students taught for a single year by a great teacher instead of an average teacher earn $\$ 50,000$ more over the course of their careers. Bau and Das (2020) uses the similar method to estimate teacher value added in Pakistan and shows that existing methods produce unbiased and reliable estimates of teacher value added despite significant differences in context. Kirkeboen, Leuven, and Mogstad (2016) examines the labor market payoffs to different types of postsecondary education, including field and institution of study with administrative data for Norway's postsecondary education system. Kuka, Shenhav, and Shih (2020) finds that Deferred Action for Childhoold Arrivals (DACA) program, which raises the expected wage earned in the US by granting work authorization and reducing the risk of deportation, increased high school completion of $19-22$ years old by $7.5 \%$ percent. Existing papers explores more about the characteris- tics in schools (such as class size, teachers) and institutional factors (DACA policy, STAR experiment). However, family members, especially parents also have huge impacts on the quantity and quality of education. Our study focuses on the role the parents play in their children's education.

\section{Education in Developing Area}

We also contribute to the literature about the connection of poverty and education. Zhang (2014) used a large-scale survey to show that high out-of-pocket educational cost is far beyond families' capacity and documented two types of education-poverty connections that co-exist in contemporary China. Due to the high educational cost, children either drop out early from school, or their families have to acquire debt and invest heavily in education. Yi et al. (2012) finds that indirect cost of education such as boarding and transportation partly explains the high drop-out rates for poor students. Bansak and Chezum (2009) studies school attrition among youth in Thailand and finds that investment in schooling are shaped by both household and local community contexts. Brown (2006) examines how parental education affects educational investment in children, focusing on investments in both goods and time. The paper finds that more educated parents expect higher returns to education for their children and make greater investments in goods and time. Chen, Adams, Qu, Wang, and Chen (2013) and Zhang (2017) take a closer look at parents' impact on children's education in the contesxt of China's increasing rural-urban migration. Our work in closely related to Brown (2006), but takes a closer look at parents' expectations about return on education, and adds another dimension: parents' time preferences.

\section{METHODOLOGY}

\section{Population and Sample Size}

The target population in this study was parents in villages in Daliang Mountain in Sichuan Province, China. Due to the lack of administrative data in rural area in China, we had to visit the households and survey parents in order to get both the demographic data and parents' beliefs about children's education.

We have established a long-term relationship with a primary school in Daliang Mountain area through voluntary teaching in previous four years(2016-2020), and even set up a scholarship to support local students from poor families. Therefore, our survey was conducted with the help from that local school and we home visted those children and read the survey to their parents (considering the probability that parents may be illiterate and unable to fill the questionnaire). 
TABLE 1. Descriptive statistics: Households in daliang mountain area

\begin{tabular}{lllll}
\hline \hline Variables & Mean & Std & Min & Max \\
\hline Total income (yr) & 17834.69 & 21969.33 & 500 & 150000 \\
Family Size (\# Children) & 4.37 & 1.30 & 1 & 7 \\
\# Children dropped out & 0.57 & 0.84 & 0 & 3 \\
Parent Age & 40.20 & 5.60 & 31 & 58 \\
Education Expenditure (pre-reform) & 591.22 & 743.22 & 50 & 4000 \\
Education Expenditure (post-reform) & 422.24 & 491.07 & 0 & \\
\hline \hline
\end{tabular}

We covered a sample size of 49 households and Table 1 presents the characteristics of those households. The average yearly income is around 17835 RMB for those 49 households, with a large standard deviation of 21969. The average income in this village is only $67 \%$ of Chinese average yearly income. And the median income is $10000 \mathrm{RMB}$, $44 \%$ of Chinese median yearly income. Also, notice that the one-child policy is not strictly implemented in this village. $96 \%$ of the households have more than one children, and the large sample size could lead to higher total expenditure on raising children and their education. The low income and large family size could both contribute to the high dropout rate observed from the data. $39 \%$ of the households had at least one children who dropped out from school. We define dropout here as not finishing the 9-year compulsory education and leave school before the age of 15 . The average education expenditure, including tuition, textbook fee etc. was around 591 RMB before the reform and shrinked to 422 RMB after the reform, which took place in year 2018. The local government waived the tuition fee entirely and provided extra subsidy (such as lunch stipend) to households in an attempt to lower the dropout rates and facilitates the elementary education.

\section{Sampling Method}

This research project focused on parents of children from the mountain areas, which is a small group of population. Also, the illiteracy of respondents have to be taken into consideration. Therefore, we home-visited the households and surveyd parents in person.

The majority of students in the primary school that we work with are from two adjacent villages. Therefore, we went to those two villages and randomly select households for the survey. We knocked at the door of every other cottage and asked them to participate in the survey. We didn't intentionally exclude families without children, but all of those households that we randomly surveyed have at least one children.

\section{Research Hypothesis}

We aim to examine the impact of parents' beliefs on education on their investment in their children's education and focus on three perspectives: their beliefs about the return on education, cost of education and patience.

H1: Parents who expected higher return on education will invest more on their children's education, and their children are less likely to drop out from school.

H2: Lower costs of education will lead to lower probability of dropouts.

H3: Parents who are more patient will invest more on their children's education, and their children are less likely to drop out from school.

We will formalize these hypotheses in the Theoretical Framework below and then present the empirical results about these hypotheses afterwards.

\section{THEORETICAL FRAMEWORK}

Education involves current costs but future returns, thus is an investment in human capital. Borrowing the Becker (2009) framework, agents maximize the present value of benefits minus the cost of education to determine the optimal education level. Suppose an agent spend first s years in school, and the total lifespan is $n$ years. The present value of benefit of schooling is:

$$
\mathrm{G}=\sum_{t=1}^{n} \frac{w_{t}^{e}-w_{t}^{u}}{(1+i)^{t}}
$$

Where $W_{t}^{e}-W_{t}^{u}$ reflects the wage difference with and without education. similarly, the present value of cost of education is:

$$
\mathrm{C}=\sum_{t=1}^{s} \frac{w_{t}^{u}+k}{(1+i)^{t}}
$$

Where $W_{t}^{u}$ is the forgone wage (without education), and $\mathrm{k}$ is the direct cost of education such as tuition. Agents will invest in education if the perceived present value of benefits exceeds the perceived present value of cost $(G>C)$.

According to this framework, we further discuss why people choose different levels of education. Note that in our 
context, parents are more likely to be the decision makers for their children's education investment.

\section{Different Benefits/Perceptions about Benefits}

As gain of education is denoted by the discounted wage difference, $\mathrm{G}=\sum_{t=1}^{n} \frac{w_{t}^{2}-w_{t}^{u}}{(1+i)^{t}}$. Parents tend to underinvest in education if they expect that the wage differences between educated and uneducated people are small.

\section{Different Costs/Perceptions about Costs}

Similarly, the cost of education is $\mathrm{C}=\sum_{t=1}^{s} \frac{W_{t}^{u}+k}{(1+i)^{t}}$. Higher cost leads to lower level of education investment, and there are two elements in the cost term, the direct cost $k$ and the indirect cost coming from the forgone wage.

\section{Patience, Different Time Preferences}

Since education involves benefits in the longer run, people will under-invest in education if they are impatient.

Those directly correspond to the three research hypotheses we had in the previous section and we will directly test these empirically in the following section.

\section{RESULTS}

\section{Expectations of Return on Education}

To examine the effect of parents' expectation of return on education on children's education outcomes, we run the following regression:

$$
y_{i}=\beta_{0}+\beta_{1}[\text { Return on } E d u c]+X_{i}+\epsilon_{i}
$$

Where $y_{i}$ are dependent variables such as dropout rates, investment in education and desired year of schooling (with- out financial constraints). And $X_{i}$ are household-level control variables such as parents " age, income, family size etc. Table 2 shows the OLS results. Column (1) and (2) reports the effect of parents' expectation of return on education on dropout rates. In Column (2), Dropout Dummy is equal to one if the household has one or more children who dropped out from school. The negative coefficient of E[Return on Educ] indicates that children whose parents expect that the return on education is high are less likely to drop out from school.

Column (3)-(5) demonstrate the effect on education investment (monetary and time). Interestingly, higher expectation of return on education doesn't necessarily generate higher expenditure on children's education. The effect on the monetary margin is insignificant. However, parents with higher expectation of return on education spend more time with their children on their homework, tutoring etc. Since most households have financial constraints in Daliang Mountain, it's difficult to make adjustments on the monetary margin. Also, the tuition is fixed for primary and middle schools, so there should be little difference in the monetary expenditure on education. However, the time spent on education is a more direct measure about parents' attitudes towards education, and it's a more flexible margin to adjust their investment. From column (6)-(7), we can see that the coefficients of E[Return on Educ] are insignificant, probably for two reasons: we have a small sample size and ask the questions only in a hypothetical way.

TABLE 2. OLS, effects of parents' expectation of return on education

\begin{tabular}{|c|c|c|c|c|c|c|c|}
\hline & (1) & (2) & (3) & (4) & (5) & (6) & (7) \\
\hline Variable & Dropout Rate & Dropout D & Expenditure $(<2018)$ & Expenditure ( $>$ 2018) & Time & Desired Educ 1 & Desired Educ 2 \\
\hline \multirow[t]{2}{*}{$\mathrm{E}$ [Return on Educ] } & -0.040 & $-0.113^{*}$ & -156.561 & -98.112 & $0.190^{*}$ & -0.618 & -0.230 \\
\hline & $(0.026)$ & $(0.065)$ & $(103.334)$ & $(66.751)$ & $(0.100)$ & $(0.428)$ & $(0.413)$ \\
\hline \multirow[t]{2}{*}{ Income } & -0.000 & -0.000 & -0.004 & 0.003 & -0.000 & $-0.000^{*}$ & 0.000 \\
\hline & $(0.000)$ & $(0.000)$ & $(0.012)$ & $(0.008)$ & $(0.000)$ & $(0.000)$ & $(0.000)$ \\
\hline \multirow[t]{2}{*}{ Children } & 0.004 & 0.091 & -58.579 & 30.996 & 0.010 & $-0.697 *$ & -0.335 \\
\hline & $(0.023)$ & $(0.058)$ & (92.509) & (59.758) & $(0.089)$ & $(0.384)$ & $(0.370)$ \\
\hline \multirow[t]{2}{*}{ Constant } & -0.108 & -0.101 & $1,254.068^{*}$ & $878.970^{*}$ & $1.936^{* * *}$ & $20.614^{* * *}$ & $16.746^{* * *}$ \\
\hline & $(0.181)$ & $(0.462)$ & (731.097) & $(472.268)$ & $(0.707)$ & (3.031) & $(2.921)$ \\
\hline Observations & 49 & 49 & 49 & 49 & 49 & 49 & 49 \\
\hline$R$-squared & 0.223 & 0.212 & 0.134 & 0.172 & 0.231 & 0.198 & 0.136 \\
\hline Controls & YES & YES & YES & YES & YES & YES & YES \\
\hline
\end{tabular}

Standard errors in parentheses ${ }^{* * *} p<0.01,{ }^{* *} p<0.05,{ }^{*} p<0.1$

Notes: Dropout Rate shows the number of children who dropped out divided by the total number of children in the household. Dropout Dummy is equal to one if the household has children who dropped out from school. Expenditure indicates the average amount of annual expenditure on education for each child, before and after 2018 (when the government began providing extra support). Time measures the axerage length of time that parents spend with children DOI: 10.20474 /jahss- 6.3 .3 on their homework, tutoring, etc. Desired level of education asks the ideal years of schooling if the government covered all the tuition (Desired Educ 1) or if the government distributed 2,000 RMB to each household per year (Desired Educ 2). Control variables include parents' age, parents' education level, and whether they worked outside the village before. 
TABLE 3. OLS, effects of costs of education

\begin{tabular}{|c|c|c|c|c|c|c|}
\hline & (1) & (2) & (3) & (4) & (5) & (6) \\
\hline Variables & Dropout Dummy & Time & Dropout Dummy & Time & Dropout Dummy & Time \\
\hline If Dropout, Income in Agricultural Work & & -8.202 & $\begin{array}{l}-20.094 \\
(13.615)\end{array}$ & (20.691) & & \\
\hline Income & $\begin{array}{l}-6.261 \\
(7.892)\end{array}$ & $\begin{array}{l}-10.570 \\
(12.084)\end{array}$ & $\begin{array}{l}-5.338 \\
(8.103)\end{array}$ & $\begin{array}{l}-8.310 \\
(12.315)\end{array}$ & $\begin{array}{l}-6.408 \\
(8.042)\end{array}$ & $\begin{array}{l}-11.697 \\
(12.208)\end{array}$ \\
\hline If Dropout, Income Working Outside & & & & & $\begin{array}{l}1.683 \\
(10.198)\end{array}$ & $\begin{array}{l}12.840 \\
(15.480)\end{array}$ \\
\hline Constant & $\begin{array}{l}-0.101 \\
(0.462)\end{array}$ & $\begin{array}{l}1.936^{* * *} \\
(0.707)\end{array}$ & $\begin{array}{l}-0.081 \\
(0.467)\end{array}$ & $\begin{array}{l}1.985^{* * *} \\
(0.710)\end{array}$ & $\begin{array}{l}-0.115 \\
(0.475)\end{array}$ & $\begin{array}{l}1.830^{* *} \\
(0.721)\end{array}$ \\
\hline Observations & 49 & 49 & 49 & 49 & 49 & 49 \\
\hline$R$-squared & 0.212 & 0.231 & 0.220 & 0.250 & 0.213 & 0.245 \\
\hline Controls & YES & YES & YES & YES & YES & YES \\
\hline
\end{tabular}

Standard errors in parentheses ${ }^{* * *} p<0.01,{ }^{* *} p<0.05,{ }^{*} p<0.1$

Notes: Dropout Dummy is equal to one if the household has children who dropped out from school. Time measures the average length of time that parents spend with children on their homework, tutoring, etc. Control variables include parents' age, expectation of return on education, parents' education level, and whether they worked outside the village before.

TABLE 4. OLS, effects of parents' patience

\begin{tabular}{llllllll}
\hline \hline & $\mathbf{( 1 )}$ & $\mathbf{( 2 )}$ & $\mathbf{( 3 )}$ & $\mathbf{( 4 )}$ & $\mathbf{( 5 )}$ & $\mathbf{( 6 )}$ & $\mathbf{( 7 )}$ \\
\hline Variable & Dropout Rate & Dropout Dummy & Expenditure (<2018) & Expenditure (> 2018) & Time & Desired Educ 1 & Desired Educ 2 \\
\hline Patient & -0.007 & -0.031 & 3.075 & 22.690 & 0.039 & $0.537^{* *}$ & 0.147 \\
& $(0.013)$ & $(0.034)$ & $(54.000$ & $(34.689)$ & $(0.052)$ & $(0.206)$ & $(0.214)$ \\
Income & -0.411 & -5.994 & $-3,874.928$ & $3,228.864$ & -10.901 & $-97.663^{*}$ & 8.034 \\
& $(3.119)$ & $(7.912)$ & $(12,663.851)$ & $(8,135.174)$ & $(12.161)$ & $(48.368)$ & $(50.299)$ \\
Constant & -0.073 & 0.053 & $1,238.891$ & 766.971 & $1.745^{* *}$ & $17.962^{* * *}$ & $16.021^{* * *}$ \\
& $(0.194)$ & $(0.492)$ & $(787.128)$ & $(505.646)$ & $(0.756)$ & $(3.006)$ & $(3.126)$ \\
Observations & 49 & 49 & 49 & 49 & 49 & 49 & 49 \\
$R$-squared & 0.229 & 0.229 & 0.134 & 0.181 & 0.243 & 0.319 & 0.147 \\
Controls & YES & YES & YES & YES & YES & YES & YES \\
\hline \hline
\end{tabular}

Standard errors in parentheses ${ }^{* * *} p<0.01,{ }^{* *} p<0.05,{ }^{*} p<0.1$

Notes: Dropout Rate shows the number of children who dropped out divided by the total number of children in the household. Dropout Dummy is equal to one if the household has children who dropped out from school. Expenditure indicates the average amount of annual expenditure on education for each child, before and after 2018 (when the government began providing extra support). Time measures the average length of time that parents spend with children on their homework, tutoring, etc. Desired level of education asks the ideal years of schooling if the government covered all the tuition (Desired Educ 1) or if the government distributed 2,000 RMB to each household per year (Desired Educ 2). Control variables include parents' age, parents' education level, and whether they worked outside the village before.

\section{Cost of Education}

Table 3 shows the OLS results for the cost of education, which includes both direct cost and indirect cost. The direct cost is the expenditure on education and the indirect cost is the income in agricultural work or the income of working outside if children drop out from school. Columns (1)-(2) report the effect of family income on dropout rate and the time parents spend studying with children. The Dropout Dummy is equal to one if the household has one or more children who dropped out from school. The negative coefficient of Income indicates that the children whose families have higher incomes are less likely to drop out from school and the parents with higher wages tend to spend less time accompanying their children studying, but those effects are not statistically significant, probably because of the limited sample size. Columns (3)-(4) report the effect of the parents' expectations on the increase in family income if their children drop out and turn to agriculture work on dropout rate and the time parents spend studying with children. Similarly, columns (5)-(6) report the effect of parents' expectation on the increase of family income if their children drop out from school and work outside instead. The coefficients are all insignificant, suggesting that the forgone income as indirect cost of education doesn't affect dropout 
rate and parents' investment in time spent studying with their children. The insignificant results suggest that financial burden is not the binding constraint, since tuition is very low because of government funding.

\section{Parents' Time Preferences}

In the survey, we asked a series of questions to measure parents' time preferences. We asked whether they preferred $150,130,120,105$ and 100 RMB a month later or 100RMB right now, respectively, and then calculated the mean of the value they chose, as an index for patience. Columns (1) and (2) report the effects of parents' patience level on dropout rates for their children. In Column (2), Dropout Dummy is equal to one if the household has one or more children who dropped out from school. The positive coefficient of patience indicates that children with more patient parents are less likely to drop out from school (though statistically insignificant). Columns (3)-(5) demonstrate the effects of patience on education investment (monetary and time). The positive coefficient shows that high patience generates higher expenditure on children's education. What's more, more patient parents spend more time with their children on their homework, tutoring, etc. The monetary and time expenditure can show the parents' attitude toward the children's education, so it is apparent that there is a positive correlation between parents' patience and their attitude. Again, those effects are not significant and should be interpreted with caution. In addition, the desired education can also represent the parents' attitude toward their children's education. In Column (6), the significant coefficient shows that more patient parents want their children have a higher level of education if the government covered all the tuition.

\section{DISCUSSION}

From the empirical results above, parents' beliefs about the return on education and their time preferences play a more significant role in education investment than the cost of education.

\section{Discussion in Terms of the High Dropout Rate}

The traditional explanation of the high dropout rate in rural China is the financial constraints (Zhang, 2014; Yi et al., 2012; Luo et al., 2012), coming from both low income levels and large family sizes. However, we find that both the direct cost and indirect cost of education have little impact on parents' education investment and dropout rates. First, with the 9-year compulsory education, the government fully funds elementary education and average expenditure on education is only around 500 RMB per year for households in this area, only a small fraction of their yearly income. Therefore, financial concerns are actually not the binding constraint for education with government support. The high dropout rate is actually related to the low expectation of return on education. Consistent with Brown (2006), parents' education levels and beliefs have significant impact on children's educational investment. Parents who don't believe in the value of education tend to underinvest in their children's education and their children could drop out from school even if the tuition is waived.

\section{Discussion in Terms of Government Funding}

We analyze parents' investment in education in the situation where government supports elementary education, which makes the cost of education less of a concern for children from poor families. However, we don't have empirical evidence about the counterfactual situation where government funding is not enough. Previous research, Zhang (2014) for instance, shows that high educational cost leads to high drop out rate. Our insignificant results about the cost of education doesn't suggest that educational cost is not the binding constraint for households in any case (instead, universal primary education is beneficial for education attainment, as discussed in Deininger (2003), but only saying that the current government support is enough to remove the financial constraint of education for households in this area.

\section{CONCLUSION}

We surveyed low-income families in the Da Liang Shan mountain area's and found that financial burdern no longer has significant effect on local parents' underinvestment on their children's education. Because of support from the government, the cost was not binding constraint any more. Instead, it is parents' attitudes, including their time preferences and beliefs about return on education, that affects investment their children's education. The students whose parents have higher expectation on educational return tend to have lower drop out rates. Also, more patient parents invest more on their children's education.

\section{LIMITATIONS AND RECOMMENDATIONS}

Small sample size is a limit of our study. Because of the illiteracy of respondents, we had to survey them in person instead of distributing the survey in papers or online, which slowed down the data collection process. Also, the small population in that area imposes a natural limit on our sample size. Because of the small sample size, we didn't manage to get significant results for some regressions, and the coefficients are noisier. However, we could still get at least some suggestive evidence from the analysis. 
There are some recommendation for the further research related to this, described as follows:

a) A study could further improve the sample to cover a large and wider population. For example, to survey more households from different villages in rural China.

b) A study could use some exogenous variation in government funding to study the effect of reducing educational cost, which has important policy implication in terms of local governments' policies on education.

c) A long-term study that follow up with students on their education level and academic performance will be helpful. We included only hypothetical questions in the survey, and real-life data from children is more credible.

\section{REFERENCES}

Altonji, J. G. (1993). The demand for and return to education when education outcomes are uncertain. Journal of Labor Economics, 11(1), 48-83. doi:https://doi.org/10.1086/298317

Arellano, M. R. (2017). Hows and whys of parental involvement in a national 'neoliberal laboratory': Aspirations, values and beliefs in relation to children's education among chilean urban lower-middle-class parents. Compare: A Journal of Comparative and International Education, 47(6), 925-941. doi:https://doi.org/10.1080/03057925.2017.1375849

Bansak, C., \& Chezum, B. (2009). How do remittances affect human capital formation of school-age boys and girls? American Economic Review, 99(2), 145-148.

Bau, N., \& Das, J. (2020). Teacher value added in a low-income country. American Economic Journal: Economic Policy, 12(1), 62-96.

Becker, G. S. (2009). Human capital: A theoretical and empirical analysis, with special reference to education. Chicago, IL: University of Chicago Press.

Bhuller, M., Mogstad, M., \& Salvanes, K. G. (2017). Life-cycle earnings, education premiums, and internal rates of return. Journal of Labor Economics, 35(4), 993-1030. doi:https://doi.org/10.1086/692509

Brown, P. H. (2006). Parental education and investment in children's human capital in rural China. Economic Development and Cultural Change, 54(4), 759-789. doi:https://doi.org/10.1086/503582

Chen, S., Adams, J., Qu, Z., Wang, X., \& Chen, L. (2013). Parental migration and children's academic engagement: The case of China. International Review of Education, 59(6), 693-722. doi:https://doi.org/10.1007/s11159-013-9390-0

Chetty, R., Friedman, J. N., \& Rockoff, J. E. (2014). Measuring the impacts of teachers I: Evaluating bias in teacher value-added estimates. American Economic Review, 104(9), 2593-2632.

Deininger, K. (2003). Does cost of schooling affect enrollment by the poor? Universal primary education in Uganda. Economics of Education Review, 22(3), 291-305. doi:https://doi.org/10.1016/S0272-7757(02)00053-5

Eckel, C., Johnson, C., \& Montmarquette, C. (2013). Human capital investment by the poor: Informing policy with laboratory experiments. Journal of Economic Behavior \& Organization, 95(8), 224-239. doi:https://doi.org/10.1016/j.jebo.2012 .02 .023

Hall, R. E., \& Jones, C. I. (1999). Why do some countries produce so much more output per worker than others? The Quarterly Journal of Economics, 114(1), 83-116. doi:https://doi.org/10.1162/003355399555954

Heckman, J. J., Humphries, J. E., \& Veramendi, G. (2018). Returns to education: The causal effects of education on earnings, health, and smoking. Journal of Political Economy, 126(1), 197-246. doi:https://doi.org/10.1086/698760

Kirkeboen, L. J., Leuven, E., \& Mogstad, M. (2016). Field of study, earnings, and self-selection. The Quarterly Journal of Economics, 131(3), 1057-1111. doi:https://doi.org/10.1093/qje/qjw019

Kuka, E., Shenhav, N. A., \& Shih, K. (2020). Do human capital decisions respond to the returns to education? Evidence from DACA. American Economic Journal: Economic Policy, 12(1), 293-324.

Luo, R., Zhang, L., Liu, C., Zhao, Q., Shi, Y., Rozelle, S., \& Sharbono, B. (2012). Behind before they begin: The challenge of early childhood education in rural China. Australasian Journal of Early Childhood, 37(1), 55-64. doi:https://doi.org/ $10.1177 / 183693911203700107$

Mincer, J. (1962). On-the-job training: Costs, returns, and some implications. Journal of Political Economy, 70(2), 50-79. doi:https://doi.org/10.1086/258725

Ng, T. W., \& Feldman, D. C. (2009). How broadly does education contribute to job performance? Personnel Psychology, 62(1), 89-134. doi:https://doi.org/10.1111/j.1744-6570.2008.01130.x 
Orazem, P. F., \& King, E. M. (2007). Schooling in developing countries: The roles of supply, demand and government policy. In, Handbook of development economics. New York, NY: Sage Publications.

Shultz, T. W. (1953). The economic organization of agriculture. New York, NY: McGraw Hill.

Smith, A. (1776). An inquiry into the nature and causes of the wealth of nations. California, CA: Wiley and John son's.

Voiculescu, F. (2009). Opportunity cost of educational human capital investment. application for the position of beneficiaryinvestor. Annales Universitatis Apulensis: Series Oeconomica, 11(2), 744-755.

Webber, D. (2014). Is the return to education the same for everybody? Retrieved from https://bit.1y/34E7dNA

Yi, H., Zhang, L., Luo, R., Shi, Y., Mo, D., Chen, X., \& Rozelle, S. (2012). Dropping out: why are students leaving junior high in China's poor rural areas? International Journal of Educational Development, 32(4), 555-563. doi:https://doi.org/ 10.1016/j.ijedudev.2011.09.002

Zhang, H. (2014). The poverty trap of education: Education-poverty connections in Western China. International Journal of Educational Development, 38(5), 47-58. doi:https://doi.org/10.1016/j.ijedudev.2014.05.003

Zhang, H. (2017). Opportunity or new poverty trap: Rural-urban education disparity and internal migration in China. China Economic Review, 44(6), 112-124. doi:https://doi.org/10.1016/j.chieco.2017.03.011 